\title{
Measuring Fibrinolysis
}

\author{
Colin Longstaff ${ }^{1 \odot}$ \\ ${ }^{1}$ Department of Biotherapeutics, National Institute for Biological \\ Standards and Control, South Mimms, Herts, United Kingdom \\ Hämostaseologie 2021;41:69-75.
}

Address for correspondence Colin Longstaff, PhD, Department of Biotherapeutics, National Institute for Biological Standards and Control, South Mimms, Herts, United Kingdom EN6 3QG (e-mail: Colin.longstaff@nibsc.org).

\begin{abstract}
Keywords

- fibrinolysis

- biomarkers

- standardization

- thrombolytics

- antifibrinolytics

Physiological fibrinolysis under normal conditions progresses slowly, in contrast to coagulation which is triggered rapidly to stop bleeding and defend against microbial invasion. Methods to detect fibrinolysis abnormalities are less simple and poorly standardized compared with common coagulation tests. Fibrinolysis can be accelerated by preparing euglobulin from plasma to reduce endogenous inhibitors, or by adding plasminogen activators to normal plasma. However, these manipulations complicate interpretation of results and diagnosis of a "fibrinolysis deficit." Many observational studies on antigen levels of fibrinolysis inhibitors, plasminogen activator inhibitor 1 or thrombin-activatable fibrinolysis inhibitor, zymogen or active enzyme have been published. However, conclusions are mixed and there are clear problems with harmonization of results. Viscoelastic methods have the advantage of being rapid and are used as point-of-care tests. They also work with whole blood, allowing the contribution of platelets to be explored. However, there are no agreed protocols for applying viscoelastic methods in acute care for the diagnosis of hyperfibrinolysis or to direct therapy. The emergence of SARS-CoV-2 and the dangers of associated coagulopathy provide new challenges. A common finding in hospitalized patients is high levels of D-dimer fibrin breakdown products, indicative of ongoing fibrinolysis. Well-established problems with D-dimer testing standardization signal that we should be cautious in using results from such tests as prognostic indicators or to target therapies.
\end{abstract}

\section{Introduction}

A simplified outline of fibrinolysis is presented in - Fig. 1 and more detailed reviews can be found elsewhere. ${ }^{1,2}$ By necessity, in response to vascular damage, coagulation must be rapid to reduce the dangers of bleeding and prevent entry of pathogenic microorganisms. Subsequently, fibrinolysis takes place slowly under normal circumstances, over hours and days as vessels are repaired. These considerations explain why there are many relatively simple, rapid, well-standardized tests to measure blood clotting, which can identify defects in coagulation pathways. However, fibrinolysis is more difficult to measure for diagnostic purposes and methods are more cumbersome, so the role of fibrinolysis in the hemostatic balance may be underestimated.

received

September 28, 20210

accepted after revision

November 26, 2020
Fibrinolysis assays are needed to study antifibrinolytic therapy and also in the development and quality control of thrombolytic drugs. Diverse approaches are available to assess fibrinolysis in healthy or sick populations to identify factors that may be involved in regulation or dysregulation, and hyperfibrinolysis or fibrinolysis resistance.

The National Institute for Biological Standards and Control (NIBSC) is a World Health Organization (WHO) collaborating center with the responsibility to generate, store and distribute biological standards. A major part of our portfolio covers diagnostic and drug-related standards in hemostasis, including fibrinolysis ${ }^{3}$ and reviews on the ways in which our biological standards can be used have been published elsewhere. ${ }^{4,5}$

$\begin{array}{ll}\text { (c) 2021. Thieme. All rights reserved. } & \text { DOI https://doi.org/ } \\ \text { Georg Thieme Verlag KG, } & \text { 10.1055/a-1325-0268. } \\ \text { Rüdigerstraße 14, } & \text { ISSN 0720-9355. } \\ 70469 \text { Stuttgart, Germany } & \end{array}$




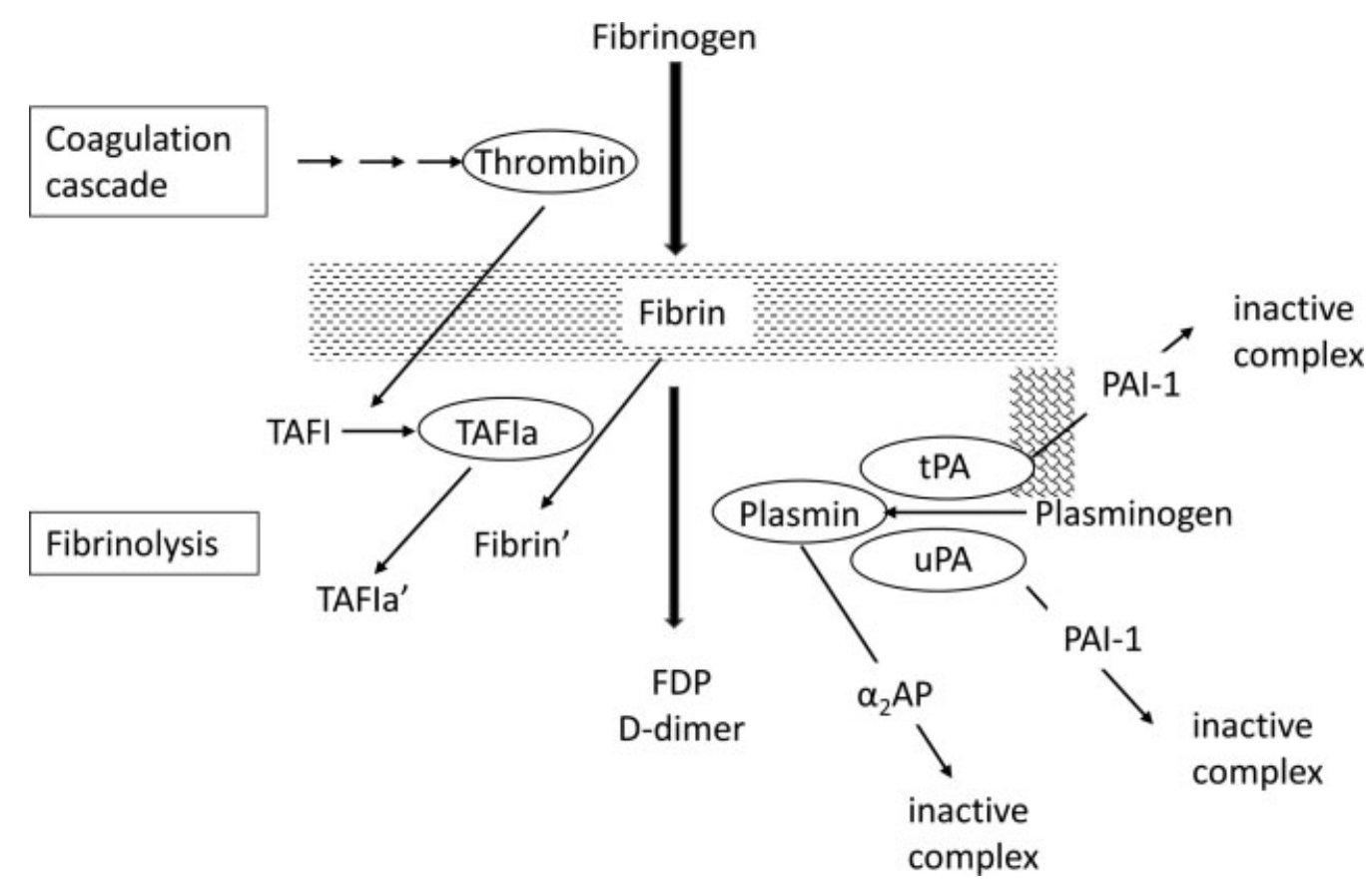

Fig. 1 Outline of the fibrinolysis system. The pathway of fibrin formation and degradation is shown by heavy arrows. Fibrin is a substrate (surface) for reactions and a substrate (target for enzymes) for plasmin. ${ }^{1}$ Fibrin degradation products (FDP) are heterogeneous in size ${ }^{88}$ and expose binding sites for D-dimer antibodies. Enzymes are in ovals and include the plasminogen activators, tissue plasminogen activator (tPA) and urokinase plasminogen activator (UPA). tPA activity is stimulated by binding to fibrin, where the finger domain is dominant, ${ }^{11,89}$ whereas uPA is generated from an inactive zymogen scuPA (not shown) by the action of plasmin. Serpin inhibitors, PAl- 1 and $\alpha_{2}$-antiplasmin ( $\alpha_{2}$-AP) form inactive complexes to reduce fibrinolysis. Thrombin-activatable fibrinolysis inhibitor (TAFI, also known as procarboxypeptidase U, or CBP2 gene product) is activated by thrombin (and plasmin, not shown), to the active form (TAFla). This enzyme modifies fibrin (shown as Fibrin') to remove C-terminal lysines, which is less effective at binding plasminogen and plasmin and more resistant to lysis. TAFla is thermally unstable and degrades to an inactive form, shown as TAFla'. Other components that are involved include $\alpha_{2}$-macroglobulin, a broad specificity inhibitor and thrombomodulin which has a role in regulating the activation of TAFI. ${ }^{90}$ Additional factors that can impair fibrinolysis include variants of fibrinogen such as $\gamma^{\prime}$-fibrinogen which affects clot architecture and fibrinogen-binding sites to make more resistant clots ${ }^{91}$ and FXIII which creates a more resistant clot by cross-linking fibrin chains and $\alpha_{2}$-AP to fibrin. ${ }^{92,93}$ The incorporation of cells into clots can also delay fibrinolysis. Platelets cause clot retraction and release PAI-194; and red blood cells can interact with fibrin, ${ }^{95}$ and also become compressed during clot retraction to form an impermeable barrier which delays clot lysis. ${ }^{96}$ PAl-1, plasminogen activator inhibitor 1.

\section{Assays for Thrombolytic Proteins}

Thrombolytics such as tissue plasminogen activator (tPA) or urokinase plasminogen activator (UPA) are serine proteases that transform plasminogen into plasmin. Microbial plasminogen binding and activating proteins such as streptokinase and staphylokinase have no intrinsic protease activity but in practice, experimentally their reaction kinetics look like other plasminogen activators and they can be analyzed in the same way (although the details of the kinetic mechanisms may be complicated ${ }^{6}$ ). In practice, investigations on enzyme mechanism and regulation, or determination of specific activity or concentration will be performed in vitro in purified systems of proteins, or in plasma-based systems and can be optimized over a chosen thrombolytic enzyme range to give the most robust results. Activities of fibrinolytic proteins are often determined relative to the WHO International Standard as a primary calibrator. ${ }^{3}$ Examples are available in publications of the development of fibrinolysis as per WHO International Standards (e.g., Locke et $\mathrm{al}^{7}$ ).

The simplest methods for following proteolytic activity involve optical monitoring of amidolytic substrates made of peptides linked to a chromophore or fluorophore. These types of substrates are not so useful when used directly on an enzyme of interest, but are valuable to study linked reactions that generate plasmin, for example. Activesite titration of serine proteases is a subgroup of chromogenic/fluorogenic assays and is useful to establish molar concentrations of active enzymes, including thrombolytic enzymes and thrombin. ${ }^{8}$ Early fibrin-based methods for measuring plasminogen activator activity used fibrin plates, but have been superseded by microtiter plate-based methods. ${ }^{9}$ This approach can be adapted to internal lysis (in which plasminogen activator is mixed with fibrinogen, plasminogen and thrombin to form a clot that is subsequently lysed evenly throughout), or external lysis (where activator is added to the top of a preformed clot). Internal lysis is related to normal hemostasis, while superficially added activator more closely reflects the situation during thrombolytic therapy. It is possible to combine fibrin-based methods and chromogenic substrate-linked measurement of plasminogen activation to precisely follow plasmin generation in the presence of fibrin. ${ }^{10,11}$ In this way, rates of plasmin generation in SI units (e.g., pM/s) for tPA, uPA and streptokinase can be compared in the same format. Comparison of WHO assigned international units (IU) for these activators is not so useful as the units are unrelated. The long-established European Pharmacopoeia method for assaying alteplase 
(tPA) activity, ${ }^{12}$ in which clot lysis time is determined by passage of a ball through the clot in a tube or release of trapped bubbles from the fibrin network, is simple and reliable. More recently, the "Halo" method has been published that uses a small volume of whole blood, clotted in a ring or halo around the edge of a microtiter-plate well. ${ }^{13}$ Lysis is followed by monitoring increasing absorbance as the clot breaks down and products released into solution.

Although it is relatively simple to generate reproducible time courses of data to study the activity of thrombolytic enzymes using these methods, the analysis of the resulting data is the next challenge. It is common in fibrinolysis assays to report lysis times, usually as time to $50 \%$ lysis, but how this is calculated is not always explained. Alternatively, zymogen activation rates determined with chromogenic substrates require the use of time squared plots, which can be tedious to generate and analyze. To standardize calculations of lysis times and zymogen activation rates and improve reproducibility, several online apps have been developed and published in association with ISTH/SSC (International Society on Thrombosis and Haemostasis/Scientific and Standardization Committee) Subcommittee on Fibrinolysis. ${ }^{14,15}$ These apps are freely available and run in a computer browser without downloading any software (see also Longstaff ${ }^{16}$ for summaries, links to apps and detailed instructions).

\section{Diagnostic Methods}

\section{Functional Tests}

Functional tests begin with the problem mentioned above that fibrinolysis without any stimulation is slow. To speed up the process, it is common to either add tPA to plasma to stimulate the generation of plasmin, or to remove inhibitors, by for example preparing the euglobulin fraction from plasma. A long-established functional method for measuring fibrinolysis in subject samples is to determine euglobulin clot lysis times (ECLTs), and this approach has been reviewed previously. $5,17,18$ The general approach is time-consuming and difficult to automate. The euglobulin fraction is reported to have a greater than $90 \%$ reduction in $\alpha_{2}$-antiplasmin, but there is also significant depletion of plasminogen activator inhibitor 1 (PAI-1) and thrombin-activatable fibrinolysis inhibitor (TAFI).$^{19}$ It is observed that the ECLT is strongly influenced by PAI- 1 (and free tPA) concentrations. Recently an updated method has been published ${ }^{20}$ where samples received added fibrinogen and ovalbumin to increase the clot turbidity. These authors also explored a fibrinolysis resistance test using added tPA which identified samples with high free active PAI-1, but also showed some sensitivity of lysis times to TAFI levels.

When normal plasma is used to investigate fibrinolysis, it is common to add significant amounts of extraneous tPA (from 200 to $700 \mathrm{ng} / \mathrm{mL}$, see Table 2 in Longstaff ${ }^{18}$ ). To generate a clot, $\mathrm{CaCl}_{2}$ is added as a minimum, and often thrombin and/or tissue factor (TF) with phospholipids may also be used. Attempts have been made to establish a standardized method for this procedure to improve reproducibility. ${ }^{21}$ A commonly used output is $50 \%$ lysis time where lysis is followed optically, and analysis can be facilitated by online apps. ${ }^{14} \mathrm{~A}$ thorough review of data from clot lysis studies has been presented to explore the relationship of fibrinolytic potential and risk for arterial and venous thrombosis. ${ }^{22}$ Conclusions from many studies are not always strong or consistent in identifying molecular risk factors in different populations. However, an important observation is that hypofibrinolysis, especially in combination with hypercoagulability, can constitute an increased thrombosis risk.

An interesting development in this area is methods to simultaneously measure generation of both thrombin and plasmin during plasma clotting and lysis. ${ }^{23}$ However, the methods proposed so far (reviewed in Longstaff ${ }^{18}$ ) have not become established, possibly because they are technically difficult to perform and analyze and no commercial equipment or software is available, in contrast to popular thrombin-generation platforms.

\section{Antigen Assays}

Antigen tests for plasma proteins involved in fibrinolysis are common and relatively simple to perform, even in large population studies. Many studies have been organized to investigate variations in circulating TPA, PAI-1 and TAFI, including free-active/inactive/latent and inhibited tPA-PAI1 complex forms, to look for associations with arterial or venous thrombosis. 24,25

Reduced levels of fibrinolysis inhibitors are not diagnosed as often as coagulation deficiencies, but when found often lead to increased bleeding risk. ${ }^{17}$ Alternatively, high circulating PAI-1 and TAFI may indicate a "fibrinolysis deficit" and thrombosis risk. There are many large-scale population studies involving PAI-1 and TAFI, but results are not consistent. ${ }^{26}$ Standardization of assay methods is poor in this area and it is not possible to directly compare absolute values of analytes from studies using different methods for PAI-1 antigen or activity or tPA antigen. ${ }^{27,28}$ Generally, elevated PAI-1 is associated with cardiovascular disease, metabolic syndrome, diabetes, obesity, senescence and as a prognostic marker for several cancers. ${ }^{29}$ It is likely that harmonization of results from different methods could be improved with common standards. ${ }^{30,31}$ However, although there are WHO International Standards for tPA antigen in plasma and PAI-1 activity, they are not so popular because they are labeled in $\mathrm{IU}$, while commercial methods report results in $\mathrm{ng} / \mathrm{mL}$. Unfortunately, the origin of the commercial kit standards is not consistent, and each "ng" is different. To establish a firm basis for reported ng, we at NIBSC are pursuing isotope dilution mass spectrometry using ${ }^{13} \mathrm{C}$-labeled recombinant proteins as a way of establishing real gravimetric concentrations of plasma analytes. Work on TAFI and PAI- 1 antigens is underway. In addition to these considerations, pre-test processing issues further complicate PAI-1 measurements and make tPA activity measurements unreliable. Factors such as diurnal and seasonal variations, ${ }^{32}$ and release of PAI-1 from platelets during venepuncture must be considered. ${ }^{33}$ Historically, a source of variation in TAFI assays has been the Thr325Ile polymorphism, which affects TAFI activation and stability. ${ }^{34,35}$ It has been proposed that TAFla is a 
more important biomarker than zymogen, ${ }^{36}$ but measurements require very sensitive methods. ${ }^{37-39}$

Interest in PAI-1 and TAFI as drug targets to modulate hemostasis has raised awareness of the importance of robust assay methods. ${ }^{40-42}$ The idea of inhibiting PAI- 1 activity is interesting in the context of aging as a mutation in the SERPINE1 gene resulting in around 50\% reduced circulating PAI- 1 is associated with longevity in animal models and a population of Amish in the United States. ${ }^{43}$

\section{Hyperfibrinolysis and Hypofibrinolysis}

Moore and colleagues ${ }^{44}$ have attempted to define or clarify different types of pathological fibrinolysis observed clinically, for instance in trauma but also in surgery and disseminated intravascular coagulation (DIC). In addition to hyperfibrinolysis, there are varieties of fibrinolysis resistance (classically identified in ECLT assays) including hypofibrinolysis (a failure to trigger fibrinolysis after clotting) and fibrinolysis shutdown (where there is a rebound of increased PAI- 1 activity and antigen after the triggering of coagulation and early release of tPA). The timing of fibrinolysis resistance and concepts such as occult fibrinolysis provide further complications. ${ }^{44}$

Hyperfibrinolysis in acute situations such as trauma or surgery is a life-threatening situation requiring rapid tests to direct treatment such as plasma or clotting factor replacements, or possibly with antifibrinolytics such as tranexamic acid (TXA). Instances where markers of fibrinolysis are elevated include trauma, DIC (where there is a fibrinolytic phenotype), ${ }^{45}$ acute promyelocytic leukemia, liver damage, congenital abnormalities and surgical procedures (reviewed in Kolev and Longstaff ${ }^{17}$ ). Common markers for ongoing fibrinolysis would be elevated D-dimer, ${ }^{46}$ raised tPA or decreased PAI-1, reduced plasminogen, reduced $\alpha_{2}$-antiplasmin and elevated plasmin- $\alpha_{2}$-antiplasmin (P-AP) complexes. Assays for these proteins are time-consuming, with the possible exception of point-of-care tests for D-dimer. However, D-dimer tests are approved for excluding thrombosis and the accurate measurement of high D-dimer levels is complicated by the low specificity of these tests and poor standardization. ${ }^{47,48}$ Where hyperfibrinolysis is detected there is a high risk of death. For instance, in trauma only a minority of patients display a hyperfibrinolysis phenotype but mortality in this group is very high. ${ }^{49,50}$ The underlying fibrinolysis imbalance is likely dominated by an increase in tPA resulting in plasmin generation with concomitant consumption of inhibitors PAI- 1 and $\alpha_{2}$-antiplasmin. ${ }^{51,52}$ The potential for hyperfibrinolysis to be associated with thrombotic complications has been highlighted previously. ${ }^{22}$

Viscoelastic methods potentially have a role in diagnosing hyperfibrinolysis and fibrinolysis resistance as they are capable of generating results more rapidly than other available methods. ${ }^{53}$ In particular, rapid thrombelastography (rTEG) has been developed to speed up clotting by stimulating both intrinsic and extrinsic coagulation using kaolin and TF activators, and making tests available in cartridge form with potential for improved reliability. ${ }^{54}$ The fundamentals of viscoelastic methods have been reviewed elsewhere ${ }^{55,56}$ and involve the analysis of clot formation and lysis by physical measurement of blood viscosity and clot strength. In practice, the common platforms rotational thromboelastometry (ROTEM) and TEG provide an array of parameters from multiple variations of clotting tests and there is no agreed way of implementing results from these tests, although attempts are being made to develop optimized algorithms. ${ }^{57,58}$ While the speed of testing is attractive, sensitivity and specificity may be an issue. A study by Raza and colleagues tested samples from trauma patients and found high P-AP complexes and D-dimer in samples where ROTEM did not detect ongoing fibrinolysis. ${ }^{49}$ It has been proposed that occult (local) fibrinolysis or the earlier production of long-lived D-dimer or P-AP complexes could be responsible for this discrepancy between fibrinolysis biomarkers and viscoelastic methods. ${ }^{44}$

An interesting and controversial aspect of these discussions is how to use antifibrinolytic therapies, particularly TXA to reduce bleeding in surgery ${ }^{59}$ or trauma. Several largescale clinical trials have demonstrated that TXA given early in trauma is safe and effective ${ }^{60}$ and pre-hospital treatment is recommended in Europe. In some quarters there are concerns that adding antifibrinolytics to a situation where there may be fibrinolysis resistance is potentially dangerous and could lead to thrombotic complications, including widespread vascular microthrombosis, organ failure and death. Thus, it is proposed that rapid testing, by viscoelastic methods, particularly rapid TEG, should be used to target only those patients who would benefit from antifibrinolytic treatment. However, several large clinical trials of TXA in trauma, ${ }^{61}$ postpartum hemorrhage ${ }^{62}$ and traumatic brain injury ${ }^{63}$ observed no increases in thromboembolic complications, ${ }^{60}$ and there is a lack of evidence of disperse microvascular thrombi. ${ }^{64,65}$ On the other hand, the HALT-IT trial, which failed to show benefit of TXA in the treatment of gastrointestinal bleeding, did observe an increased risk of venous thromboembolic events (deep vein thrombosis plus pulmonary embolism) in the TXA treatment group. ${ }^{66}$ The authors speculated that the increased risk may be due to disturbed hemostasis in the liver cirrhosis and variceal bleeding patients that made up half the subjects in the study, and/or the high dose of TXA used ( $4 \mathrm{~g}$ over 24 hours), which may also explain an observed increase in seizures. The conclusions from many studies and systematic reviews seem to be that more research is needed before there is sufficient confidence in viscoelastic methods for routine diagnostic testing, although there are promising signals of benefit in situations to reduce blood component use. ${ }^{67-69}$ Hard evidence from randomized controlled trials to support the application of viscoelastic methods in targeting antifibrinolytic therapy is lacking. ${ }^{50,70}$ It is argued that without this evidence the established risks of TXA treatment delay should outweigh theoretical but unproven risks of nontargeted treatment.

As TXA treatment is delayed, it becomes progressively less effective and after 3 hours benefit is lost ${ }^{60}$ and the dangers appear to be excess bleeding, not thrombosis. There are few 
studies of uPA in pathological fibrinolysis, but Hijazi and colleagues $^{71}$ have identified the slow development of a peak of uPA after several hours in a mouse model of brain injury, following the earlier rise and decay of tPA. We have shown in vitro that TXA plus urokinase stimulates plasmin generation to aggravate consumption of $\alpha_{2}$-antiplasmin, which is often reduced in trauma patients, to allow the fibrinolytic system to go unchecked. The consequences are destruction of fibrinogen and clotting factors, which could contribute to a bleeding pathology. ${ }^{72}$ There are little data available on changes in UPA or UPA-PAI complexes in trauma patients and currently tests for these analytes are poorly standardized so that estimates of gravimetric or molar concentrations in patient plasma are unreliable.

\section{Covid-19}

Coagulopathy was soon observed to be a life-threatening complication of infection with SARS-CoV-2 in hospitalized patients. $^{73,74}$ Venous thromboembolic events are noted in many patients in intensive care and a high proportion of patients are diagnosed with pulmonary embolism. ${ }^{75,76}$ Postmortem investigations have identified widely distributed microvascular thrombi in the lungs, heart, kidney, liver, skin and fat. ${ }^{77}$ Biomarkers in severely ill patients include raised fibrinogen and D-dimer, which can reach very high levels, ${ }^{77,78}$ often $>2 \mu \mathrm{g} / \mathrm{mL}$, many times over the routine cut-off used to exclude a diagnosis of thrombosis $(0.5 \mu \mathrm{g} / \mathrm{mL})$. D-dimer has been investigated as a marker to predict mortality and manage patient care and direct anticoagulant treatment. ${ }^{74,79}$ Reporting results and standardization of D-dimer testing protocols is an area of concern in Covid-19 patients and is particularly important if it is to be linked to patient care ${ }^{80}$ Given the prevalence of thrombotic complications in Covid-19 patients in intensive care, it is not surprising that thrombolytic therapy with IPA is being considered for seriously ill patients via the intravenous route ${ }^{81}$ or in nebulizer form..$^{82}$ Other factors that may influence coagulation and fibrinolysis in Covid-19 patients may include neutrophil extracellular trap (NET) formation, which stimulates coagulation and retards fibrinoly$\operatorname{sis}^{83,84}$ and NETs have been observed in some early studies with samples from Covid-19 patients. ${ }^{77,85,86}$ There is interest in changes in PAI-1 levels during Covid-19 infection, and there are early reports of fibrinolysis resistance assessed by antigen studies and viscoelastic methods. ${ }^{85,87}$

\section{Conclusions}

There is a long history of fibrinolysis research and assay method development, but no simple direct methods to establish something like a fibrinolysis capacity or a measurement of fibrinolysis resistance on par with prothrombin time or activated partial thromboplastin time, for example. Many problems associated with poor standardization and assay variability remain unresolved. Rapid universal methods would be useful in situations such as trauma, DIC and surgery, but there is a need for large-scale randomized trials to establish safety and efficacy. A better understanding is needed of changes in fibrinolysis following infection with agents causing hemorrhagic diseases, and the emergence of SARS-CoV-2 coagulopathy highlights the need for ongoing research to improve the measurement of fibrinolysis.

\section{Conflict of Interest}

The authors declare that they have no conflict of interest.

\section{References}

1 Longstaff C, Kolev K. Basic mechanisms and regulation of fibrinolysis. J Thromb Haemost 2015;13(Suppl 1):S98-S105

2 Rijken DC, Lijnen HR. New insights into the molecular mechanisms of the fibrinolytic system. J Thromb Haemost 2009;7(01): 4-13

3 Thelwell C. Fibrinolysis standards: a review of the current status. Biologicals 2010;38(04):437-448

4 Coxon CH, Longstaff C, Burns C. Applying the science of measurement to biology: Why bother? PLoS Biol 2019;17(06):e3000338

5 Longstaff C, Whitton CM, Stebbings R, Gray E. How do we assure the quality of biological medicines? Drug Discov Today 2009;14 (1-2):50-55

6 Huish S, Thelwell C, Longstaff C. Activity regulation by fibrinogen and fibrin of streptokinase from Streptococcus pyogenes. PLoS One 2017;12(01):e0170936

7 Locke M, Rigsby P, Longstaff C SSC Communication on behalf of the Fibrinolysis Subcommittee. An international collaborative study to establish the WHO 4th International Standard for Streptokinase: communication from the SSC of the ISTH. J Thromb Haemost 2020;18(06):1501-1505

8 Thelwell C. Biological standards for potency assignment to fibrinolytic agents used in thrombolytic therapy. Semin Thromb Hemost 2014;40(02):205-213

9 Beebe DP, Aronson DL. An automated fibrinolytic assay performed in microtiter plates. Thromb Res 1987;47(01):123-128

10 Longstaff C, Whitton CM. A proposed reference method for plasminogen activators that enables calculation of enzyme activities in SI units. J Thromb Haemost 2004;2(08):1416-1421

11 Silva MM, Thelwell C, Williams SC, Longstaff C. Regulation of fibrinolysis by C-terminal lysines operates through plasminogen and plasmin but not tissue-type plasminogen activator. J Thromb Haemost 2012;10(11):2354-2360

12 European Commission. Alteplase for injection. Monograph, European Pharmacopoeia, 2007. European Pharmacopoeia; Strasbourg 2013:1170

13 Bonnard T, Law LS, Tennant Z, Hagemeyer CE. Development and validation of a high throughput whole blood thrombolysis plate assay. Sci Rep 2017;7(01):2346

14 Longstaff C Subcommittee on Fibrinolysis. Development of Shiny app tools to simplify and standardize the analysis of hemostasis assay data: communication from the SSC of the ISTH. J Thromb Haemost 2017;15(05):1044-1046

15 Rosendaal FR, Reitsma PH. Reproducibility. J Thromb Haemost 2017;15(05):833

16 Longstaff C. Shiny-Clots. Updated 2019. Accessed November, 2020 at: https://drclongstaff.github.io/shiny-clots/

17 Kolev K, Longstaff C. Bleeding related to disturbed fibrinolysis. $\mathrm{Br} \mathrm{J}$ Haematol 2016;175(01):12-23

18 Longstaff $C$. Measuring fibrinolysis: from research to routine diagnostic assays. J Thromb Haemost 2018;16(04):652-662

19 Smith AA, Jacobson LJ, Miller BI, Hathaway WE, Manco-Johnson MJ. A new euglobulin clot lysis assay for global fibrinolysis. Thromb Res 2003;112(5-6):329-337

20 Ilich A, Noubouossie DF, Henderson M, et al. Development and application of global assays of hyper- and hypofibrinolysis. Res Pract Thromb Haemost 2019;4(01):46-53 
21 Pieters M, Philippou H, Undas A, de Lange Z, Rijken DC, Mutch NJSubcommittee on Factor XIII and Fibrinogen, and the Subcommittee on Fibrinolysis. An international study on the feasibility of a standardized combined plasma clot turbidity and lysis assay: communication from the SSC of the ISTH. J Thromb Haemost 2018;16(05):1007-1012

22 Lisman T. Decreased plasma fibrinolytic potential as a risk for venous and arterial thrombosis. Semin Thromb Hemost 2017;43 (02):178-184

23 van Geffen M, van Heerde WL. Global haemostasis assays, from bench to bedside. Thromb Res 2012;129(06):681-687

24 Kyrle PA, Rosendaal FR, Eichinger S. Risk assessment for recurrent venous thrombosis. Lancet 2010;376(9757):2032-2039

25 Smith A, Patterson C, Yarnell J, Rumley A, Ben-Shlomo Y, Lowe G. Which hemostatic markers add to the predictive value of conventional risk factors for coronary heart disease and ischemic stroke? The Caerphilly Study. Circulation 2005;112(20):3080-3087

26 Meltzer ME, Doggen CJ, de Groot PG, Rosendaal FR, Lisman T. The impact of the fibrinolytic system on the risk of venous and arterial thrombosis. Semin Thromb Hemost 2009;35(05):468-477

27 Declerck PJ, Moreau H, Jespersen J, Gram J, Kluft C. Multicenter evaluation of commercially available methods for the immunological determination of plasminogen activator inhibitor-1 (PAI1). Thromb Haemost 1993;70(05):858-863

28 Gram J, Declerck PJ, Sidelmann J, Jespersen J, Kluft C. Multicentre evaluation of commercial kit methods: plasminogen activator inhibitor activity. Thromb Haemost 1993;70(05):852-857

29 Song C, Burgess S, Eicher JD, O'Donnell CJ, Johnson AD. Causal effect of plasminogen activator inhibitor type 1 on coronary heart disease. J Am Heart Assoc 2017;6(06):e004918

30 Dempfle CE, Zips S, Ergül H, Heene DLFibrin Assay Comparative Trial study group. The Fibrin Assay Comparison Trial (FACT): evaluation of 23 quantitative D-dimer assays as basis for the development of D-dimer calibrators. FACT study group. Thromb Haemost 2001;85(04):671-678

31 Meijer P, Haverkate F, Kluft C, de Moerloose P, Verbruggen B, Spannagl M. A model for the harmonisation of test results of different quantitative D-dimer methods. Thromb Haemost 2006; 95(03):567-572

32 Rudnicka AR, Rumley A, Lowe GD, Strachan DP. Diurnal, seasonal, and blood-processing patterns in levels of circulating fibrinogen, fibrin D-dimer, C-reactive protein, tissue plasminogen activator, and von Willebrand factor in a 45 -year-old population. Circulation 2007; 115(08):996-1003

33 Macy EM, Meilahn EN, Declerck PJ, Tracy RP. Sample preparation for plasma measurement of plasminogen activator inhibitor-1 antigen in large population studies. Arch Pathol Lab Med 1993; 117(01):67-70

34 Schneider M, Boffa M, Stewart R, Rahman M, Koschinsky M, Nesheim M. Two naturally occurring variants of TAFI (Thr-325 and Ile-325) differ substantially with respect to thermal stability and antifibrinolytic activity of the enzyme. J Biol Chem 2002;277 (02):1021-1030

35 Frère C, Morange PE, Saut N, et al. Quantification of thrombin activatable fibrinolysis inhibitor (TAFI) gene polymorphism effects on plasma levels of TAFI measured with assays insensitive to isoform-dependent artefact. Thromb Haemost 2005;94(02): 373-379

36 Tregouet DA, Schnabel R, Alessi MC, et al;AtheroGene Investigators. Activated thrombin activatable fibrinolysis inhibitor levels are associated with the risk of cardiovascular death in patients with coronary artery disease: the AtheroGene study. J Thromb Haemost 2009;7(01):49-57

37 Neill EK, Stewart RJ, Schneider MM, Nesheim ME. A functional assay for measuring activated thrombin-activatable fibrinolysis inhibitor in plasma. Anal Biochem 2004;330(02):332-341

38 Heylen E, Van Goethem S, Augustyns K, Hendriks D. Measurement of carboxypeptidase $U$ (active thrombin-activatable fibrinolysis inhibitor) in plasma: Challenges overcome by a novel selective assay. Anal Biochem 2010;403(1-2):114-116

39 Ceresa E, Brouwers E, Peeters M, Jern C, Declerck PJ, Gils A. Development of ELISAs measuring the extent of TAFI activation. Arterioscler Thromb Vasc Biol 2006;26(02):423-428

40 Hendrickx ML, Zatloukalova M, Hassanzadeh-Ghassabeh G, Muyldermans S, Gils A, Declerck PJ. Identification of a novel, nanobodyinduced, mechanism of TAFI inactivation and its in vivo application. J Thromb Haemost 2014;12(02):229-236

41 Wyseure T, Rubio M, Denorme F, et al. Innovative thrombolytic strategy using a heterodimer diabody against TAFI and PAI- 1 in mouse models of thrombosis and stroke. Blood 2015;125(08): 1325-1332

42 Willemse JL, Heylen E, Nesheim ME, Hendriks DF. Carboxypeptidase U (TAFla): a new drug target for fibrinolytic therapy? J Thromb Haemost 2009;7(12):1962-1971

43 Khan SS, Shah SJ, Klyachko E, et al. A null mutation in SERPINE1 protects against biological aging in humans. Sci Adv 2017;3(11): 01617

44 Moore HB, Moore EE, Neal MD, et al. Fibrinolysis shutdown in trauma: historical review and clinical implications. Anesth Analg 2019;129(03):762-773

45 Gando S, Levi M, Toh CH. Disseminated intravascular coagulation. Nat Rev Dis Primers 2016;2:16037

46 Weitz JI, Fredenburgh JC, Eikelboom JW. A test in context: Ddimer. J Am Coll Cardiol 2017;70(19):2411-2420

47 Longstaff C, Adcock D, Olson JD, et al. Harmonisation of D-dimer a call for action. Thromb Res 2016;137:219-220

48 Jennings I, Woods TA, Kitchen DP, Kitchen S, Walker ID. Laboratory D-dimer measurement: improved agreement between methods through calibration. Thromb Haemost 2007;98(05):1127-1135

49 Raza I, Davenport R, Rourke C, et al. The incidence and magnitude of fibrinolytic activation in trauma patients. J Thromb Haemost 2013;11(02):307-314

50 Gall LS, Brohi K, Davenport RA. Diagnosis and treatment of hyperfibrinolysis in trauma (A European Perspective). Semin Thromb Hemost 2017;43(02):224-234

51 Cardenas JC, Matijevic N, Baer LA, Holcomb JB, Cotton BA, Wade $\mathrm{CE}$. Elevated tissue plasminogen activator and reduced plasminogen activator inhibitor promote hyperfibrinolysis in trauma patients. Shock 2014;41(06):514-521

52 Chapman MP, Moore EE, Moore HB, et al. Overwhelming tPA release, not PAI-1 degradation, is responsible for hyperfibrinolysis in severely injured trauma patients. J Trauma Acute Care Surg 2016;80(01):16-23; discussion 23-25

53 Cotton BA, Faz G, Hatch QM, et al. Rapid thrombelastography delivers real-time results that predict transfusion within 1 hour of admission. J Trauma 2011;71(02):407-414, discussion 414-417

54 Neal MD, Moore EE, Walsh M, et al. A comparison between the TEG 6s and TEG 5000 analyzers to assess coagulation in trauma patients. J Trauma Acute Care Surg 2020;88(02):279-285

55 Ilich A, Bokarev I, Key NS. Global assays of fibrinolysis. Int J Lab Hematol 2017;39(05):441-447

56 Whiting D, DiNardo JA. TEG and ROTEM: technology and clinical applications. Am J Hematol 2014;89(02):228-232

57 Baksaas-Aasen K, Van Dieren S, Balvers K, et al;TACTIC/INTRN Collaborators. Data-driven development of ROTEM and TEG algorithms for the management of trauma hemorrhage: a prospective observational multicenter study. Ann Surg 2019;270(06):1178-1185

58 Juffermans NP, Wirtz MR, Balvers K, et al;TACTIC Partners. Towards patient-specific management of trauma hemorrhage: the effect of resuscitation therapy on parameters of thromboelastometry. J Thromb Haemost 2019;17(03):441-448

59 Ker K, Prieto-Merino D, Roberts I. Systematic review, metaanalysis and meta-regression of the effect of tranexamic acid on surgical blood loss. Br J Surg 2013;100(10):1271-1279

60 Gayet-Ageron A, Prieto-Merino D, Ker K, Shakur H, Ageron FX, Roberts IAntifibrinolytic Trials Collaboration. Effect of treatment 
delay on the effectiveness and safety of antifibrinolytics in acute severe haemorrhage: a meta-analysis of individual patient-level data from 40138 bleeding patients. Lancet 2018;391(10116): 125-132

61 Roberts I, Shakur H, Afolabi A, et al;CRASH-2 Collaborators. The importance of early treatment with tranexamic acid in bleeding trauma patients: an exploratory analysis of the CRASH-2 randomised controlled trial. Lancet 2011;377(9771):1096-1101, 1101.e1-1101.e2

62 Shakur H, Roberts I, Fawole B, et al;WOMAN Trial Collaborators. Effect of early tranexamic acid administration on mortality, hysterectomy, and other morbidities in women with post-partum haemorrhage (WOMAN): an international, randomised, double-blind, placebo-controlled trial. Lancet 2017;389(10084):2105-2116

63 CRASH-3 Trial Collaborators. Effects of tranexamic acid on death, disability, vascular occlusive events and other morbidities in patients with acute traumatic brain injury (CRASH-3): a randomised, placebo-controlled trial. Lancet 2019;394(10210):1713-1723

64 Cole E, Davenport R, Willett K, Brohi K. Tranexamic acid use in severely injured civilian patients and the effects on outcomes: a prospective cohort study. Ann Surg 2015;261(02):390-394

65 Van Haren RM, Valle EJ, Thorson CM, et al. Hypercoagulability and other risk factors in trauma intensive care unit patients with venous thromboembolism. J Trauma Acute Care Surg 2014;76 (02):443-449

66 Collaborators HALT-ITHALT-IT Trial Collaborators. Effects of a high-dose 24-h infusion of tranexamic acid on death and thromboembolic events in patients with acute gastrointestinal bleeding (HALT-IT): an international randomised, double-blind, placebocontrolled trial. Lancet 2020;395(10241):1927-1936

67 Hunt H, Stanworth S, Curry N, et al. Thromboelastography (TEG) and rotational thromboelastometry (ROTEM) for trauma induced coagulopathy in adult trauma patients with bleeding. Cochrane Database Syst Rev 2015;2(02):CD010438

68 Wikkelsø A, Wetterslev J, Møller AM, Afshari A. Thromboelastography (TEG) or thromboelastometry (ROTEM) to monitor haemostatic treatment versus usual care in adults or children with bleeding. Cochrane Database Syst Rev 2016;(08):CD007871

69 Rugeri L, Levrat A, David JS, et al. Diagnosis of early coagulation abnormalities in trauma patients by rotation thrombelastography. J Thromb Haemost 2007;5(02):289-295

70 Roberts I. Fibrinolytic shutdown: fascinating theory but randomized controlled trial data are needed. Transfusion 2016;56 (Suppl 2):S115-S118

71 Hijazi N, Abu Fanne R, Abramovitch R, et al. Endogenous plasminogen activators mediate progressive intracerebral hemorrhage after traumatic brain injury in mice. Blood 2015;125(16):2558-2567

72 Longstaff C, Locke M. Increased urokinase and consumption of $\alpha_{2}$ -antiplasmin as an explanation for the loss of benefit of tranexamic acid after treatment delay. J Thromb Haemost 2019;17(01): 195-205

73 Iba T, Levy JH, Levi M, Connors JM, Thachil J. Coagulopathy of coronavirus disease 2019. Crit Care Med 2020;48(09):1358-1364

74 Langer F, Kluge S, Klamroth R, Oldenburg J. Coagulopathy in COVID-19 and its implication for safe and efficacious thromboprophylaxis. Hamostaseologie 2020;40(03):264-269

75 Klok FA, Kruip MJHA, van der Meer NJM, et al. Confirmation of the high cumulative incidence of thrombotic complications in critically ill ICU patients with COVID-19: An updated analysis. Thromb Res 2020;191:148-150

76 Middeldorp S, Coppens M, van Haaps TF, et al. Incidence of venous thromboembolism in hospitalized patients with COVID-19. J Thromb Haemost 2020;18(08):1995-2002

77 Becker RC. COVID-19 update: Covid-19-associated coagulopathy. J Thromb Thrombolysis 2020;50(01):54-67
78 Giusti B, Gori AM, Alessi M, et al. Sars-CoV-2 induced coagulopathy and prognosis in hospitalized patients: a snapshot from Italy. Thromb Haemost 2020;120(08):1233-1236

79 Zhang L, Yan X, Fan Q et al. D-dimer levels on admission to predict in-hospital mortality in patients with Covid-19. J Thromb Haemost 2020;18(06):1324-1329

80 Thachil J, Longstaff C, Favaloro EJ, Lippi G, Urano T, Kim PYSSC Subcommittee on Fibrinolysis of the International Society on Thrombosis and Haemostasis. The need for accurate D-dimer reporting in COVID-19: communication from the ISTH SSC on fibrinolysis. J Thromb Haemost 2020;18(09):2408-2411

81 Barrett CD, Moore HB, Moore EE, et al. Fibrinolytic therapy for refractory COVID-19 acute respiratory distress syndrome: Scientific rationale and review. Res Pract Thromb Haemost 2020;4(04): 524-531

82 Whyte CS, Morrow GB, Mitchell JL, Chowdary P, Mutch NJ. Fibrinolytic abnormalities in acute respiratory distress syndrome (ARDS) and versatility of thrombolytic drugs to treat COVID-19. J Thromb Haemost 2020;18(07):1548-1555

83 Longstaff C, Varjú I, Sótonyi P, et al. Mechanical stability and fibrinolytic resistance of clots containing fibrin, DNA, and histones. J Biol Chem 2013;288(10):6946-6956

84 Varjú I, Longstaff C, Szabó L, et al. DNA, histones and neutrophil extracellular traps exert anti-fibrinolytic effects in a plasma environment. Thromb Haemost 2015;113(06):1289-1298

85 Weiss E, Roux O, Moyer JD, et al. Fibrinolysis resistance: a potential mechanism underlying COVID-19 coagulopathy. Thromb Haemost 2020;120(09):1343-1345

86 Zuo Y, Yalavarthi S, Shi H, et al. Neutrophil extracellular traps in COVID-19. JCI Insight 2020;5(11):138999

87 Nougier C, Benoit R, Simon M, et al. Hypofibrinolytic state and high thrombin generation may play a major role in SARS-COV2 associated thrombosis. J Thromb Haemost 2020;18(09): 2215-2219

88 Walker JB, Nesheim ME. The molecular weights, mass distribution, chain composition, and structure of soluble fibrin degradation products released from a fibrin clot perfused with plasmin. J Biol Chem 1999;274(08):5201-5212

89 Longstaff C, Thelwell C, Williams SC, Silva MM, Szabó L, Kolev K. The interplay between tissue plasminogen activator domains and fibrin structures in the regulation of fibrinolysis: kinetic and microscopic studies. Blood 2011;117(02):661-668

90 Bajzar L, Morser J, Nesheim M. TAFI, or plasma procarboxypeptidase B, couples the coagulation and fibrinolytic cascades through the thrombin-thrombomodulin complex. J Biol Chem 1996;271 (28):16603-16608

91 Uitte de Willige S, Standeven KF, Philippou H, Ariëns RA. The pleiotropic role of the fibrinogen gamma' chain in hemostasis. Blood 2009;114(19):3994-4001

92 Duval C, Allan P, Connell SDA, Ridger VC, Philippou H, Ariëns RAS. Roles of fibrin $\alpha$ - and $\gamma$-chain specific cross-linking by FXIIIa in fibrin structure and function. Thromb Haemost 2014;111(05): 842-850

93 Fraser SR, Booth NA, Mutch NJ. The antifibrinolytic function of factor XIII is exclusively expressed through $\alpha_{2}$-antiplasmin crosslinking. Blood 2011;117(23):6371-6374

94 Whyte CS, Mitchell JL, Mutch NJ. Platelet-mediated modulation of fibrinolysis. Semin Thromb Hemost 2017;43(02):115-128

95 Wohner N, Sótonyi P, Machovich R, et al. Lytic resistance of fibrin containing red blood cells. Arterioscler Thromb Vasc Biol 2011;31 (10):2306-2313

96 Cines DB, Lebedeva T, Nagaswami C, et al. Clot contraction: compression of erythrocytes into tightly packed polyhedra and redistribution of platelets and fibrin. Blood 2014;123(10): 1596-1603 